\title{
O PROCESSO DE BOLONHA NO ESPAÇO EUROPEU E A REFORMA UNIVERSITÁRIA BRASILEIRA
}

\section{Carmen Célia Barradas Correia Bastos}

\section{RESUMO}

Este artigo aborda questões que envolvem o movimento de reformas educacionais na educação superior, a partir do final do Século XX, como a Declaração de Bolonha assinada em 1999, por ministros da Educação europeus, e que promove, atualmente, a reforma chamada Processo de Bolonha. Outros documentos como a Declaração Mundial sobre Educação Superior, 1998, representam marco referencial das reformas a que se refere este texto. Em sua essência, os documentos europeus vinculam o movimento reformista da educação superior às necessidades contextualizadas pelo padrão de globalização da economia. São articulações que têm como base o incentivo à competitividade, mobilidade discente, adaptação ao mercado de trabalho. No Brasil, em que sentido é possível situar os reflexos desse movimento? Na busca desse entendimento, focalizamos o movimento empreendido pelo Ministério da Educação para discutir a reforma universitária para o país, em especial destacamos o Seminário Internacional Universidade XXI e a Declaração de Brasília. Resguardadas as especificidades de cada situação, vislumbramos refletir sobre possíveis intersecções dos movimentos reformistas na educação superior contemporânea.

\section{PALAVRAS-CHAVE}

Processo de Bolonha; Reforma universitária; Educação superior

\section{THE BOLOGNA PROCESS IN THE EUROPEAN SPACE AND THE BRAZILIAN HIGHER EDUCATION REFORM}

\begin{abstract}
This article approaches questions that involve the movement of educational reforms in the higher education, from the end of Century XX, until the Declaration of Bologna signed in 1999, by European ministers of Education that promoted the reform called Bologna Process. Other documents as the World-wide Declaration on Higher Education, 1998, represent referential landmark of the reforms that this text is related to. In its essence, the European documents tie the reformist movement of the higher education to the necessities contextualized by the economy globalization standard. They are have as base the competitiveness encouragement, learning mobility, and adaptation to the work market. In Brazil, where is possible to point out the consequences of this movement? Searching for this agreement, we focus the movement undertaken by the Ministry of Education to discuss the university reform for the country; in special we highlight the International Seminary University XXI and the Declaration of Brasilia. Protected the specificities of each situation, we intend to reflect on possible interspecies of the reformist movements in the higher contemporary education.
\end{abstract}

\section{KEYWORDS}

Bologna process; University reform; Higher education 


\section{REFORMAS PARA EDUCAÇÃO SUPERIOR: REFLEXÕES SOBRE O SENTIDO DAS PROPOSTAS}

O termo "reforma” tem significado estrito de “nova organização, nova forma”, de acordo com o dicionário Larousse Cultural da Língua Portuguesa (1999). O sentido de uma reforma no campo educativo tem sempre a ver com respostas ao sistema econômico e político de uma época. Sempre que há mudanças no plano econômico ou político, estas provocam grandes reformas educacionais. Na era da globalização, marco na economia mundial, propostas de reforma educacional se apresentam em praticamente todos os continentes. De um modo geral, uma reforma representa, segundo Canário (1992, p. 198), “uma mudança em larga escala, com caráter imperativo para o território nacional, implicando opções políticas, a redefinição de finalidades e objetivos educativos, alterações estruturais no sistema que se aplica”. Sacristán (1996), numa análise mais crítica sobre as reformas, afirma que, sob a denominação "reformas”, tem guarida uma gama de iniciativas e programas com propósitos muito variados, daí a tendência a qualificar qualquer ação normal sobre o sistema educacional como "programa de reforma”. Para esse autor, "na política educacional, as reformas substituem, muitas vezes, a carência de um sistema de inovação e atualização permanentes, de uma política cotidiana, para melhorar as condições do sistema educacional” (SACRISTÁN, 1996, p. 54).

Etimologicamente, o termo “inovação", vem do latim innovatio, “introdução de alguma novidade na legislação, nos costumes, na ciência, nas artes” (cf. Grande Dicionário Larousse Cultural da Língua Portuguesa, 1999). Este é um conceito estrito do termo, pois entendemos que as reformas podem ou não trazer inovação. Conforme Fernandes (2000, p. 48), “se toda a inovação transporta consigo uma intenção de mudança, nem toda mudança introduz necessariamente inovação". O que se pretende distinguir é o sentido de inovação que as mudanças do mundo contemporâneo estão a exigir. São situações emergenciais que muitas vezes precisam de "reformas", ou legislação, que busquem "inovar", diante de resistências a padrões já inoperantes, ou que produzem exclusões do mundo em constantes transformações. A inovação, no sentido educativo, tem características próprias. Nem sempre o que é previsto nas reformas educacionais significa inovação do projeto educativo. A inovação a que nos referimos, tem a ver com a sintonia, com o vínculo nas mudanças do cenário mundial e social que se vive. A mudança que produz inovações é a que nos interessa.

Os conceitos de reforma, de inovação ligam-se, em sua origem, com uma questão abrangente e que gera todas as demais situações: a crise. 
Do grego krísis, a palavra “crise” tem hoje seu significado estendido às transformações decisivas em qualquer aspecto da vida social, pessoal, institucional. A existência de uma crise não pode significar uma situação final, sem solução, ao contrário, deve proporcionar ações renovadoras, reflexões importantes para decisões fundamentais. $\mathrm{Na}$ atual conjuntura, tanto as reformas, quanto as mudanças que promovem inovações têm origem, geralmente, em ambientes que são afetados por crises. È preciso compreender as causas da crise para compreender o sentido das reformas e, conseqüentemente, apreender o resultado institucional das ações promovidas para superação, ou não, da crise. O movimento de transição provocado pela crise no mundo das ciências e no mundo econômico, que alteram o social, o individual, o institucional, contextualiza o momento presente. É a crise das mudanças de um tempo, do avanço científico e tecnológico que inclui o sujeito conhecedor como centro das mudanças para inovações. Sob nosso ponto de vista, os desafios advindos da globalização da economia, caracterizam uma crise institucional, vivenciada pela educação superior européia, em face da exigência de integração dessas instituições históricas, ao novo projeto econômico desafiador imposto, especialmente pelos Estados Unidos e Japão, com suas redes tecnológicas sofisticadas que dão base à economia mundial.

O sentido das proposições reformistas presentes no final do século $\mathrm{XX}$, para a educação superior, em âmbito mundial, vincula-se às mudanças impostas pelo processo de globalização econômica que permeia o mundo contemporâneo. Nesta perspectiva como desdobramentos da construção da União Européia, seus impatos sobre a educação superior e suas relações com a economia, a Declaração de Bolonha provoca um programa de reforma da educação superior na Europa que deve consolidar-se até o ano de 2010. Há a exigência implícita de uma educação superior que forneça as bases da inovação, da competitividade e da produtividade, características marcantes da economia globalizada.

No Brasil, os efeitos da onda globalizadora também são impactantes para vários segmentos. A educação superior "moderniza-se" a partir da diversificação do locus de formação acadêmica, da introdução da educação à distância, por exemplo, que fazem parte da legislação aprovada em 1996 como a Lei de Diretrizes e Bases para Educação (LDB 9.394/96), e que traz, pela primeira vez, capítulos específicos sobre a educação superior brasileira, integrados nessa forma de lei. Dando continuidade às propostas de reformas instituídas pelo governo FHC, por intermédio das mudanças introduzidas pela LDB, a partir do ano de 2003, o primeiro governo Lula promove uma grande discussão sobre o que passou a ser chamada, “reforma universitária”, em tempos de democracia. 
É o conjunto dessas duas propostas reformistas que pretendemos discutir nesse artigo: O Processo de Bolonha no espaço europeu e a reforma universitária brasileira, com a intencionalidade de vislumbrar possíveis intersecções desse movimento, como característica da uma educação superior contemporânea.

\section{O ESPAÇO EUROPEU DE EDUCAÇÃO SUPERIOR}

O Processo de Bolonha se coloca no cenário das proposições para a educação superior como semente promissora de articulações políticas de reformas significativas para o ensino superior no âmbito mundial. É uma reforma que corresponde ao propósito da construção do Espaço Europeu da Educação Superior, coeso, competitivo e atrativo para docentes e alunos europeus e de outros países com intenções de promover a mobilidade de docentes, de estudantes e a empregabilidade de diplomados.

A Declaração da Sorbonne1 (25 de Maio de 1998), deu início à criação de uma Área Européia de Ensino Superior como um mecanismo para promover a mobilidade de alunos e docentes, possibilitar a empregabilidade dos cidadãos Europeus e o desenvolvimento econômico e social da Europa.2

Em Junho de 1999, os Ministros da Educação de 29 Estados Europeus, subscreveram a Declaração de Bolonha que contém, como objetivo, o estabelecimento até 2010, do Espaço Europeu de Educação Superior, com a finalidade de alcançar os objetivos: a) aumentar a competividade e a atratividade em nível internacional à educação superior européia; b) melhorar a adaptação da formação dos graduados europeus às demandas do mercado de trabalho; d) desenvolver a mobilidade interna e externa de alunos. Uma das metas é estabelecer um sistema uniforme de créditos, organizado a partir de ciclos de estudos.

No seguimento do compromisso político assumido em Bolonha, os Ministros da Educação europeus reunidos em Praga, em maio de 2001, reconheceram a importância e a necessidade de mais três linhas de ação para o andamento do processo:

- Promoção da aprendizagem ao longo da vida;

- Maior envolvimento dos estudantes na gestão das instituições de Ensino Superior;

\footnotetext{
1 Em reunião de Ministros da Educação da Alemanha, Itália, França e Reino Unido, foi assinado em Paris, a Declaração de Sorbonne com a intenção de construírem um Espaço Europeu de Ensino Superior.

2 Neste contexto, a UNESCO sediou a Conferência mundial para a educação superior, em Paris, de 05 a 09 de outubro de 1998, da qual foi aclamada a Declaração Mundial sobre Educação Superior.
} 
- Promoção da atratibilidade do Espaço Europeu do Ensino Superior

Em outro comunicado feito em setembro de 2003, os Ministros responsáveis pela Área da Educação Superior de 33 Países Europeus, reuniram-se em Berlim com o objetivo de avaliar o processo de construção do Espaço Europeu do Ensino Superior. Ficou estabelecido então, que, até 2005, o ECTS (European Credit Transfer System)3 e o Suplemento ao Diploma4 deveriam estar em pleno funcionamento; e o esforço de sinergias entre Espaço Europeu do Ensino Superior e Espaço Superior de Investigação, definidos como pilares fundamentais, à consolidação da Sociedade do Conhecimento. (MCES, Portugal, 2004).

De acordo com o Ministério da Ciência e do Ensino Superior de Portugal, (2004)

O Processo de Bolonha representa um desafio tão importante como os que estão definidos na Estratégia de Lisboa5 e que visam para a Europa os perfis próprios de um espaço econômico mais dinâmico e competitivo do mundo baseado no conhecimento e capaz de garantir um crescimento econômico sustentável, com mais e melhores empregos e com maior coesão social. (Ministério da Ciência e do Ensino Superior de Portugal, 2004).

A lógica do Processo de Bolonha é justamente ser um coadjuvante das estratégias empreendidas pela União Européia no que diz respeito à educação superior. A questão central que se coloca é a comparabilidade de formações diferentes para efeitos de reconhecimento internacional e de mobilidade, de transparência da melhoria efetiva da qualidade das formações. Altera-se a estrutura acadêmica curricular que passa a ser dividida em três ciclos: o primeiro, geral, com três anos de duração, seguido de uma formação profissional de até três anos e um doutorado para aqueles que quiserem dedicar-se à pesquisa.

O que pode acontecer com a introdução do sistemas de ciclos é que, um primeiro ciclo de formação superior graduada, com relevância para o mercado de trabalho, pode ser visto como implementações de relações de trabalho mais flexíveis e a diminuição dos custos de mão-de-obra, para promover a competitividade Européia e, ao mesmo tempo, diminuir os encargos públicos com a educação superior, tornando-se assim, resultados práticos das políticas neoliberais.

\footnotetext{
3 Sistemas de créditos baseados nas horas de estudo que um aluno necessita para adquirir as competências definidas em cada disciplina. Um crédito é equivalente a 25 - 30 horas de estudos e um ano letivo equivale a um total de 60 créditos. Este sistema foi criado para facilitar a comparação entre os graus de ensino, e promover a mobilidade.

4 São informações adicionais sobre a universidade, o programa, objetivos de aprendizagem, conceitos obtidos pelo aluno, com objetivo de dar visibilidade ao processo de formação profissional.

5 Estratégia de Lisboa representa uma agenda de estratégias para a União Européia, de março de 2000, que elegeu o emprego, as reformas econômicas e a coesão social como partes integrantes de uma economia baseada no conhecimento.
} 
O sistema de educação superior europeu, sempre teve como característica uma diversidade de estruturas de graus, diferenciação nos períodos de estudos, diversas formas de acesso, etc, que tende a ser completamente alterado com a implementação do Processo de Bolonha. Durante muito tempo, esta característica foi considerada como uma das grandes vantagens competitivas da Europa. Com a reforma em curso, estes modelos desaparecerão diante da uniformização curricular exigida?

\section{O CONTEXTO HISTÓRICO DAS REFORMAS NA EDUCAÇÃO SUPERIOR BRASILEIRA}

Com o pretexto de situarmos como ponto de partida histórico-institucional das reformas na educação superior brasileira, portanto, - sem a intenção de aprofundar a questão histórica relevante que a envolve, - fazemos uma breve referência aos movimentos reformistas havidos na educação superior brasileira, como início de discussão.

A História da educação superior brasileira é recente, se considerarmos a história das universidade no contexto latino-americano. Criada no século XX, com o "Estatuto das Universidades Brasileiras” (1931), a educação superior viveu, então, sua primeira reforma. Antes desse período não havia uma organização institucional da educação superior, embora existisse a oferta de ensino superior em faculdades isoladas. Até a década de 1960, o contexto legislativo foi dado pelo Decreto 19.851/1931, do Governo de Getúlio Vargas, pós-Revolução de 1930.

O segundo contexto de reforma universitária vivido pela educação superior brasileira, deu-se após 30 anos da criação do sistema universitário. A Lei 5.540/1968 promulgada pelo governo militar do Presidente Costa e Silva que promoveu a reforma e, pelo contexto autoritário da ditadura militar que empreendia delírios de criação de uma nação-potência, a educação superior foi convocada a dar suporte à modernização, flexibilidade administrativa e formação de recursos humanos de alto nível para o desenvolvimento do país (art. $1^{\mathrm{o}}$ da Lei $5.540 / 68)$.

O Brasil democrático, do final do século $\mathrm{XX}$, em especial a partir do primeiro governo de Fernando Henrique Cardoso, (1995-1998) participou de eventos internacionais que discutiam os encaminhamentos para educação e, no contexto de discussões sobre educação superior, destacamos a Conferência Mundial de Educação Superior, realizada em Paris em outubro de 1998, que reuniu mais de 180 países de todos os continentes. O objetivo principal da Conferência foi o de discutir os desafios que a educação superior deveria enfrentar no século XXI; Articular transformações no âmbito da universidade para dar conta 
das exigências da chamada sociedade do conhecimento e também pensar num processo que promovesse uma sociedade melhor, mais includente.

Passados cinco anos da Conferência Mundial, a UNESCO convocou, em 2003, uma nova Conferência, a Paris + 5, com o objetivo de analisar as ações pós Conferência Mundial sobre Educação Superior. O Brasil foi representado pelo então Ministro da Educação, Cristovam Buarque, que como orador principal do evento, conclamou a todas as universidades do mundo a promoverem uma revolução, abrindo seus muros, passando a ser uma universidade aberta a todos, unificadas e sem fronteiras. Embora o evento, Paris +5 , não tenha tido a repercussão da Conferência de 1998, este serviu de reafirmação da necessidade de todos olharem para a educação superior como importante segmento institucional que deveria ser reformado com vista a enfrentar a realidade do século XXI.

Nesta perspectiva, o Ministério da Educação do Brasil realizou o Seminário Internacional Universidade XXI - Novos Caminhos para a Educação Superior: o Futuro em Debate, realizado em Brasília no período de 25 a 27 de novembro de 2003, com o objetivo de promover um amplo debate sobre o panorama da educação superior no mundo contemporâneo, visando obter subsídios para mais uma reforma do sistema brasileiro de educação superior.

Os debates no Seminário apontavam para a característica fundamental da atual crise da educação superior, como sendo sua incapacidade de enfrentar respondendo aos desafios das demandas do mundo globalizado. Ainda foi discutido que os sérios problemas da educação superior, dizem respeito à insuficiência de oportunidades educacionais, em muitas realidades, no mundo todo. O problema do acesso e da qualidade da educação superior, são ícones dos principais problemas da crise da educação superior no Brasil.

Do Seminário Internacional Universidade XXI, foi elaborada a Declaração de Brasília. O documento sinaliza textualmente:

\footnotetext{
Numa sociedade com elevados índices de pobreza e de analfabetismo, discriminação étnica e racial, ausência de serviços de educação e de saúde em níveis de qualidade e em quantidades desejáveis, impõe-se um planejamento educacional, em todos os níveis, voltado para o desenvolvimento multilateral, equilibrado e sustentável, comprometido com a erradicação da miséria e com a igual distribuição de oportunidades. (Declaração de Brasília, 2003).
}

Os eixos que nortearam as discussões e impulsionaram a elaboração de propostas para reforma da educação superior, sinalizaram para a questão das políticas de democratização e acesso, além da diversificação das modalidades de ensino. 
O anteprojeto de lei que estabelece a chamada Lei de Reforma da Educação Superior, (Projeto de Lei 7200/2006) está em discussão no Congresso Nacional. O texto legislativo traz as normas gerais para a educação superior no país e propõe algumas alterações na LDB/1996, em especial destacamos a possibilidade das universidades estruturarem os cursos de graduação, organizando-os em ciclos.

\section{EM QUE SENTIDO HÁ CONVERGÊNCIAS NOS MOVIMENTOS REFORMISTAS EUROPEU E BRASILEIRO?}

Aparentemente os propósitos da nossa análise parecem incabíveis, inconcebíveis, considerando-se que as realidades continentais, européia e brasileira, são tão distantes. Entretanto, intencionamos refletir sobre o sentido das reformas que estão ocorrendo na educação superior contemporaneamente e essa postura nos provoca a busca de aproximações, intersecções, haja vista concebermos, como ponto de partida, um mundo globalizado, onde as ações reformistas acabam quase sempre por alcançarem objetivos similares.

No cenário de transformações da sociedade contemporânea, pressionados pela ordem produtivista do mundo globalizado, mais uma vez a educação superior é provocada a participar do processo no sentido de atualizar-se frente aos desafios seja de ordem social ou econômica. Uma convergência inegável que ocorre num nível mundial, diz respeito ao eixo orientador de todas estas mudanças que se situam na dimensão economicista, neoliberal, impostas pelos organismos internacionais, como o Banco Mundial, que são sintonizados ao padrão da globalização. O Processo de Bolonha não é outra coisa senão a resposta da Europa, organizada politicamente como União Européia, aos padrões de competividade, aligeiramento da formação profissional, com vistas à integração de sujeitos ao mercado de trabalho. É a “modernzação” da educação superior do continente europeu que se organiza em um espaço comum para a educação superior. Questões como a unificação do sistema (ECTS), têm o objetivo de promover a mobilidade de alunos e professores naquele espaço, principalmente. Uma das intenções das mudanças na educação superior européia, notadamente do Espaço Europeu de Educação Superior, seria a de promover um sistema integrado de ensino, um sistema universitário compatível e transparente na proposta de formação, com vistas ao desenvolvimento econômico da região.

No Brasil, apesar da educação superior ser instituída a partir de um conjunto de normas que regulariza o sistema universitário brasileiro, existem críticas no sentido de que não se pode dizer que no Brasil exista “um sistema universitário”. Segundo Buarque (2003) 
“nossas universidades, apesar dos esforços [...] formam um conjunto que não possui a clareza de um sistema integrado”. Há a necessidade de, por exemplo, uma regularização quanto as transferências de alunos, que hoje é muito difícil por incompatibilidade de grades curriculares. A questão da mobilidade discente só é prevista no anteprojeto de reforma (PL 7200/2006) no que se refere à transferência para cursos afins, na hipótese de existência de vagas e mediante processo seletivo. Não há mudança, muito menos inovação na reforma, tampouco similaridade com a proposta européia.

Quanto à estruturação dos cursos como possibilidade de ciclos de estudos, é colocada como opção para as universidades incluírem um período de formação geral, em quaisquer campos do saber, com duração mínima de quatro semestres, com o propósito de desenvolver: a) formação humanística, científica, tecnológica e interdisciplinar; b) estudos preparatórios para os níveis superiores de formação; e c) orientação para escolha profissional.

Este seria um ponto de aproximação entre as reformas aqui estudadas. O Processo de Bolonha prevê a organização da educação superior em ciclos, uniformizados, para garantir a mobilidade dos alunos e mais rápida inserção no mercado de trabalho. Na reforma brasileira, a criação de estruturas em ciclos, embora opcional, tem como objetivo possibilitar uma formação acadêmica menos especializada, tecnicista, e dar uma ênfase na formação humanista, ausente dos nossos currículos.

\section{CONSIDERAÇÕES FINAIS}

Na tentativa de responder a pergunta provocativa, temos a convicção de que estamos diante de processos de reformas da educação superior em decorrência da necessidade da universidade transformar-se, adequar-se às exigências do mundo contemporâneo. Porém, estas reformas são alimentadas por eixos bem definidos e embora tenham um alinhamento à solicitação produtivista do mercado capitalista, esta é mais marcante no Processo de Bolonha da União Européia, do que na reforma brasileira da educação superior.

A reforma brasileira tem uma preocupação mais acentuada nas questões das políticas de democratização do acesso e de assistência estudantil, aos programas de ações afirmativas e inclusão social, que devem atender ou superar as condições históricas, culturais e educacionais dos diversos segmentos sociais do país. A diversificação da oferta de ensino como possibilidade de democratizar, e o estímulo à educação à distância como forma de universalizar a educação superior, são questões próprias da nossa realidade, da nossa jovem universidade. 
A preocupação com a mobilidade, a competitividade, características do Processo de Bolonha, não se coloca, portanto, como centralidade das discussões no contexto brasileiro porque grande parte dos jovens ainda são excluídos da educação superior pública no país. O acesso igualitário à educação superior de qualidade, conquistado pelo velho mundo, não é uma realidade brasileira. A reforma da educação superior brasileira é, sob nosso ponto de vista, mais interna no sentido de solucionar históricos problemas de débitos sociais perversos.

Nessa perspectiva, entendemos a reforma brasileira como proposta mais alinhada às proposições dos documentos da UNESCO ( Declaração Mundial para Educação Superior e Paris +5 ) do que propriamente às idéias que têm norteado a implementação do Processo de Bolonha fortemente vinculados às questões de ordem econômico-sustentável do mundo globalizado. A nossa reforma vincula-se às questões dos direitos humanos, justiça social, multiculturalidade e promoção de acesso das minorias. O modelo da estrutura acadêmica atual (graduação num único ciclo, numa concepção fragmentada do conhecimento e de especialização precoce) não será alterado, a não ser nas universidades que ousarem romper com esse padrão acadêmico, e possibilitarem inovações curriculares.

No conjunto das políticas afirmativas de acesso igualitário e reformas inovadoras na estrutura curricular, é que esperamos acontecer uma verdadeira reforma na educação superior.

\section{REFERÊNCIAS}

BRASIL. Lei $\mathbf{n}^{\mathbf{0}}$ 9.394, de 20 de dezembro de 1996. Estabelece as diretrizes e bases da educação nacional.

BUARQUE, C. A universidade numa encruzilhada. Trabalho apresentado na Conferência Mundial de Educação Superior + 5, UNESCO, Paris, 23 -25 de junho de 2003.

CALAME, P. A universidade no século XXI: por um novo contrato com a sociedade. Conferência de abertura da $8^{\mathrm{a}}$ consulta coletiva Unesco/ONG sobre o ensino superior, Paris 13 a 15 de janeiro, 2003.

CALVINO, I. Seis propostas para o próximo milênio: lições americanas. São Paulo: Companhia das Letras, 1990.

CANÁRIO, R. Inovação e projeto educativo de escola. Lisboa: Educa, 1992.

CARVALHO, A. Projeto educativo. 3. ed. Porto: Afrontamento, 1999.

CATANI, A.; OLIVEIRA, J. Educação superior no Brasil: reestruturação e metamorfose das universidades públicas. Petrópolis: Vozes, 2002.

(c) ETD - Educação Temática Digital , Campinas, v.9, n. esp., p.95-106, dez. 2007 - ISSN: 1676-2592. 
. et al. Política educacional, mudanças no mundo do trabalho e reforma curricular dos cursos de graduação. Educação \& Sociedade, Campinas, Centro de Estudos Educação e Sociedade (CEDES), n. 75, p. 67-83, 2001.

DECLARAÇÃo DE BRASíLIA. Documento divulgado no endereço eletrônico do Ministério da Educação e Cultura. Acesso em: dez. 2003.

DECLARAÇÃO MUNDIAL SOBRE EDUCAÇÃO SUPERIOR NO SÉCULO XXI. São Gonçalo: Universo, 1999.

DELORS, J. Educação, um tesouro a descobrir. 2. ed. São Paulo/Brasília:

Cortez/Ministério da Educação (MEC)/Organização Educacional, Científica e Cultural das Nações Unidas (UNESCO), 1999.

FÁVERO, M. L. Universidade do Brasil: das origens à construção. Rio de Janeiro: Editora UFRJ, 2000.

FLEXA, R. et al. As novas desigualdades educativas. In: CASTELLS, M. Novas perspectivas críticas em educação. Porto Alegre: Artes Médicas, 1996, p. 33-42.

GRANDE DICIONÁRIO Larousse Cultural. São Paulo: Nova Cultural, 1990.

HORTALE, V.; MORA, J.G. Tendências das reformas da educação superior na Europa no contexto do Processo de Bolonha. Educação e Sociedade, São Paulo, v. 25 n. 88 Número Especial - 2004.

IANNI, O. A era do globalismo. Rio de Janeiro: Civilização Brasileira, 1999.

MINISTÉRIO DA CIÊNCIA E DO ENSINO SUPERIOR - Processo de Bolonha disponível em: mces@mces.gov.pt. Acesso em: 2004.

PEREIRA, A. C. Visão e ação: a universidade no século XXI. Rio de Janeiro. Editora da UERJ, 1999.

RIBEIRO, M. Políticas para a educação superior no cone sul: do autoritarismo ao neoliberalismo. Pro-Posições, Campinas, Faculdade de Educação da UNICAMP, v. 11, n. 03(33), p. 55-94, 2000.

SACRISTÁN, J. G. Reformas educacionais: utopia, retórica e prática. In:

SILVA, T.; GENTILI, P. Escola S.A. quem ganha e quem perde no mercado educacional do neoliberalismo. Brasília: Confederação Nacional dos Trabalhadores em Educação (CNTE), 1996. p. 50-74.

. A educação que temos, a educação que queremos. In: IMBERNÓN, F. A educação no século XXI. Porto Alegre: Artmed, 2000, p. 37-63.

SAVIANI, D. A nova lei da educação: trajetórias, limites e perspectivas. Campinas: Autores Associados, 1997.

(c) ETD - Educação Temática Digital , Campinas, v.9, n. esp., p.95-106, dez. 2007 - ISSN: 1676-2592. 
